\title{
natureINSIGHT
}

\section{SUSTAINABLE ECOSYSTEMS AND SOCIETY}

6 November 2014 / Vol 515 / Issue No 7525

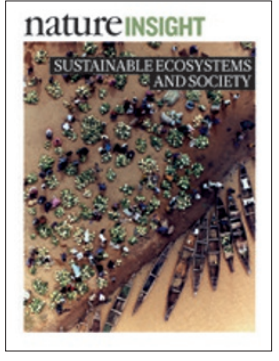

Cover image

Andreas Buerkert

Zakari Soumana

\section{Editor, Nature}

Philip Campbell

Publishing

Richard Hughes

Production Editor

Jenny Rooke

Art Editor

Nik Spencer

Sponsorship

Reya Silao

Production

lan Pope

Marketing

Steven Hurst

Editorial Assistant

Melissa Rose
The Macmillan Building

4 Crinan Street

London N1 9XW, UK

Tel: +44 (0) 2078334000

e: nature@nature.com

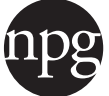

nature publishing group
$\mathrm{W}$

e are living in the Anthropocene epoch, the period of time in which human actions have a dominant influence on many of Earth's physical and biological processes. These processes, which are organized into ecosystems, are, in turn, responsible for providing humanity with many essential goods and services. It is therefore important that we rein in our impacts so that ecosystems can operate in a sustainable way, without severe loss or change of function.

This Insight explores the two-way relationship between humanity and natural ecosystems, addresses how it can be managed sustainably and illustrates it with examples from several crucially important systems.

One of the most obvious services that ecosystems provide is food. Graeme Cumming and his co-authors look at terrestrial agriculture and how it has shaped recent societal changes, such as urbanization. The sustainable management of agriculture is a major challenge in a world that is increasingly urbanized and in which most people's lives are far removed from the fields that produce their food.

Even an urbanized world cannot isolate itself from what may at first seem to be detrimental natural processes. Max Moritz and his colleagues discuss the three-way relationship between societies, ecosystems and fire, and how it can be put on a sustainable footing.

Finally, James Watson, Nigel Dudley, Daniel Segan and Marc Hockings look at one of the most successful approaches to curbing human influence and preserving natural ecosystems: protected areas. In both marine and terrestrial systems, protected areas can allow ecosystems to provide goods and services sustainably, and maintain global biodiversity. The authors discuss how well such areas are actually performing and what actions need to be taken to maintain them.

\section{Patrick Goymer Senior Editor}

\section{CONTENTS}

\section{REVIEWS}

50 Implications of agricultural transitions and urbanization for ecosystem services

Graeme S. Cumming, Andreas Buerkert, Ellen M. Hoffmann, Eva Schlecht, Stephan von Cramon-Taubadel\& Teja Tscharntke

58 Learning to coexist with wildfire Max A. Moritz, Enric Batllori, Ross A. Bradstock, A. Malcolm Gill, John Handmer, Paul F. Hessburg, Justin Leonard, Sarah McCaffrey, Dennis C. Odion, Tania Schoennagel \& Alexandra D. Syphard

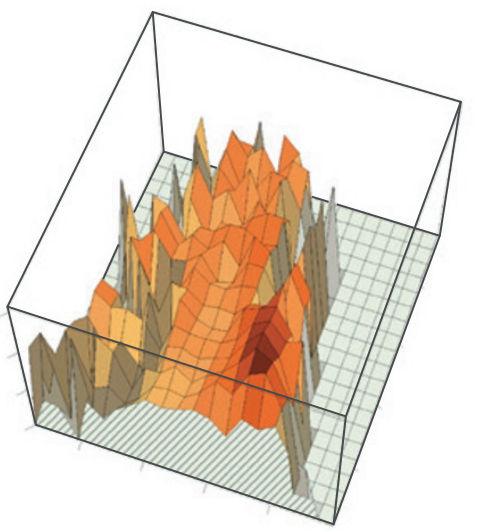

67 The performance and potential of protected areas James E. M. Watson, Nigel Dudley, Daniel B. Segan \& Marc Hockings

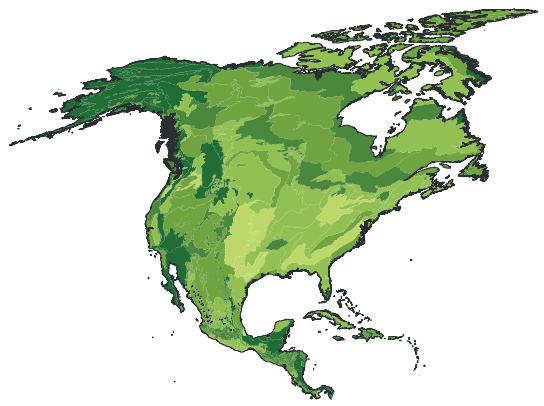

